\title{
Communicative competence of students in technical specialties.
}

\author{
Kalandarova Safiya Tockirovna ${ }^{1}$ \\ Kulmamatov Oybek Amonovich ${ }^{2}$ \\ ${ }^{1}$ Tashkent Institute of Irrigation and agricultural mechanization Engineers department of "English" \\ ${ }^{2}$ Tashkent Institute of Architecture and Construction, senior teacher of "Foreign languages" department
}

\begin{abstract}
This article discusses the teaching of foreign languages the future technology of foreign language specialties in the textile industry.

Keywords: textile speciality, lingvoculture, direction of technology, literature, foreign language, technical institute of higher education, competence, forming of term, in a professional speaking another language, lingvoculturology, communication, language and culture, cognitive, general competence, preparation for future speciality, textile industry.
\end{abstract}

\section{. INTRODUCTION}

An analysis of current trends and the development of national in systems of higher education and project in new state educational standards of higher professional education, regulations in the field of engineering education in the field of foreign languages training of Students in textile specialties shows actually lingvo-cultural orientation of training in line with the formation of intercultural competence and training specialties. Training future engineers lingvocultural competence facilitates integration of acquired knowledge into a coherent picture of the world, thus helping future professional to solve communication problems in the sphere of professional activity. This unit contributes to the application of the requirements of time to spend future professional to search and analyze information necessary for studying advanced foreign experience, as well as work with the technical literature, in particular the textile industry, and documentation in a foreign language. However, it should be noted that in the current practice in Uzbekistan, teaching discipline «Foreign language» in technical colleges are obvious gaps.

1. No divergent courses students toward specialties relevant department.

2. Not defined structure, content and conditions of foreign language professionally oriented communicative competence.

3. Not resolved the complex communicative professionally oriented tasks specific to a particular level of education and continuous multi-level structure of the course (in years of schooling).

All of this leads to the fact that graduates of technical colleges, even with a fairly high level of formation in foreign language communicative competence, experience difficulties in the process of professional dialogue with specialists from other countries, due to the aborted linguistic competence profile, insufficient multicultural outlook and insufficient personal behavioral characteristics which lead to a number of conflicts in addressing quality of training. Formation of professional foreign language training of future specialists in technical colleges requires a high level of professional and foreign language competence, which provides intercultural communication and build effective communication links with foreign partners, and a successful career in a foreign environment.

Therefore, in these conditions, the problem of improving foreign language training in technical specialties in universities is particularly important.

The importance of linguistic-cultural competent in the process of intercultural communication is defined by special role in integrating its continent and ensuring the relationship of language and culture. If we consider that in terms of intercultural communication learner perceive it through comparison with their own culture, where foreign language acts as a mediator of culture, ect... linguistic-cultural competent, as a key element in the formation of intercultural competence and being characterized by multi-faced and integrative capacity emphasizes its holistic nature. Possession of linguistic-cultural competent of intercultural communication means possession of studying a foreign language and a system of knowledge about the culture of the target language country, as reflected in the national language, knowledge and skills to use them in intercultural communication, hence the ability to follow not only the rules of conduct of a linguistic society, but also 
language features, which include a terminological lexicon, terminology has been each language, in common brings it closer to other languages, something of their own specific, due not only to its internal laws of development, but also the nature of the phenomena of perception of reality.

Achieving the purpose of education is provided by the Students mastering the content of vocational and foreign language training, consisting of basic and vocational-oriented courses. This is due to the fact that the basic course provides the formation of a common foreign language competence, ect, foundation training underlying the state educational standarts of higher educational and is common for all technical fields.

Vocational and foreign language communicative competence is the «integrative quality of the future specialist with complex structure organization».

It includes three components of motivational value (interest in professional foreign language training and awareness of its importance for future activites), cognitive activity (combining) foreign language communicative competence in the field of professional and general (on the subject) competence is a professional a-important qualities and the ability to engineer, emotionally-volitional (associated with selfesteem and skills generation of feelings of responsibility for success in academic and future professional activity).

As a basis for the organization of the process in formation of professional competence of foreign language students in technical colleges is the technology of contextual learning that accelerate the formation on the basic of general and specific competencies and professional foreign language competence.

The term «competence» is understood intellectually and personally due to a persons ability to practice, and «competence» is defined as a substantial component of this ability in the form of knowledge, skills (I.A.Zimnyaya, M.Y.Yerdakinov, ect...). According I.A.Zimnyaya, competence always is actual manifestation of competences.

On the one hand, foreign language professional communicative competence based on the unity oriented with professional, informational, linguistic, communicative, social, behavioral, cultural, ethical, strategic, ideological and individual personality components. On the other hand, the future specialist should possess integrated system of categories, which includes the following components: a key qualification, professionalism, professor, skills, readiness, professional, competence, professional education.

Consequently, in the modernization of the system of higher education quality the aim of training future professionals is the formation of competence, ensuring effective interaction with the environment in a particular area. Competence is an integrative concept and of motivational, cognitive, behavioral, value semantic emotional and volitional components.

In developing the methodological technique should be clear:

1. Material (technical text), which is the subject of study.

2. The amount of material that is used for acquisition of terminological lexicon the scientific literature. A is important that the number of root words and their derivatives are often used in technical texts, do not overload closes.

3. The concept of "term". Terms defined in German as "Fachwort", it is essentially a word or phrase a special (scientific, technical of language produced (host borrowed etc.,) for exact expression of specific concepts and notations specific subjects.

Define the concept of the term means to describe the method of its construction from the constitutional equal: For example, it is difficult a word "Farbzusammenstellung" often used in the textile industry consists of two components: the first component which "Farb" is a truncated word.

"Farbe" means:1.color, paint,complexion.

2. paint (colorant).

3. as a symbol of the identity of the party or organization.

4.quatry,color.

5.color

Compound words "Zusammenstellung" consisting of two components zusammen +stellung and meaning "the selection of colors" is an indication that the amount of information of all the components the whole words are not all the information is a compound word because it is the first of "zusammen" means together, and indicates a convergence on the connection. Consequently, substantial aspect is the mastery of a foreign language and studying the system of background knowledge related to the culture and history of the people. At the same native language and culture are the "terms" for comparison (L.V.Sherba). As the practice of training terminological lexicon of the textile industry, a methodical approach to our students has always proved fruitful, so that when it is the systematic use of students began to understand the meaning of new words 
in a logical way. These requirements imply comprehensive training of future professionals in engineering activities in accordance with international standarts and national specifics of the language in vocational training, which plays a leading role terminological competence. These requirements should ensure that:

- Understanding the nature and significance of specialist in a particular area.

- Ability to use different method to communicate effectively in professional environment and society (writing reports, presentation materials, delivery and reception of clear and accessible instructions)

- At least professional competence speaking another language, terminology base necessary for communication when working with colleagues from other countries or in international teams.

- Awareness of the practical issues of project activities.

- Creative research within the profession.

- The need for and ability to scientific growth and self - education.

Given the lack of vocabulary for the textile industry and the importance of learning the vocabulary of terminology need a holistic approach to the problem of selection of terms based on the thematic division of scientific knowledge, which is impossible without applying the method of logical semantic analysis of the conceptual and terminological textile industry and the establishment of terminological lexicon in teaching logic, conceptual and lexical relationships between the terms and structure - morphemic analysis terms. This will facilitate their adequate perception and correct translation from German into Uzbek or Russian. In addition the exact

vocabulary semantization terminology facilitates the perception and learning vocabulary, as well as contributes to the formation of terminology "baggage" of students etc....Their professional and foreign language competence, in particular the formation of reading and understanding the communicative sense of special technical text, thus the professional communication. In other words, the formation of professional and foreign language competence of students in the textile specialty involves such components as target, substantial, procedural and efficient competent.

The theoretical foundations of the process in formation. Terms line lexicalization nomination Action process.

\section{Literature.}

1. Andrienko A.S. Development of foreign language professional communicative competence of students in a technical college (on the basis of credit-modular technology of training). AK

2. Rostov - on-Don.2007 page.

3. O.S.Akhmanova. Dictionary of linguistic terms. Publisher "Soviet encyclopedia" Moscow 1969 page 474.

4. Plavlishak T.A. Linguistic-culture interpretation of a work of art as a component in teacher training foreign language (French) M 2007 page 18.

5. Patyaeva N.V. Formation of professional competence of students in language, engineers building specialties in contextual training. AK. Below Novgorod. 2007 page 11. 